\title{
Nitrogenous fertilizers and the production of crops and grass
}

\author{
By W. Holmes and D. T. A. Aldrich, Wye College (University of London), \\ Ashford, Kent
}

Great strides have been made in the study and application of farm-management economics in recent years. This consideration of the principles of economics and husbandry governing agricultural production has led to a wide realization of the importance of the law of diminishing returns and an appreciation that the basic information essential to the application of this law to agriculture is extremely scanty. Since the quantity of fertilizers used in this country in particular, and in agriculture in general, has expanded enormously in recent years, examination of the available evidence in this field is considered to be of importance and interest. When applied to fertilizer practice, the law of diminishing returns may be interpreted very simply as meaning that for every additional unit of fertilizer applied the crop response is smaller than the response to the previous unit; the response curve is logarithmic and not linear. In this review, the physical response to increasing applications of nitrogenous fertilizer by crops and grass is considered not in terms of money but as cwt. of starch equivalent ( $\mathrm{I}$ cwt. S.E. = I I9,950 Cal. net energy) which is the most suitable common unit of measurement for the wide variety of crop types concerned.

The law of diminishing returns defines the general relationships between fertilizer and crop response but the precise shape of the response curve is modified by many factors including soil conditions, climate, crop variety and crop management. However, some information is available on the average response curve to nitrogen for specific crops, calculated from data collected from a range of conditions. The classical work in this field was done by Crowther \& Yates (194I). Using material from this study, Yates \& Boyd (I949) calculated the responses to increasing nitrogen applications of a number of crops. These are shown graphically in Fig. $x$.

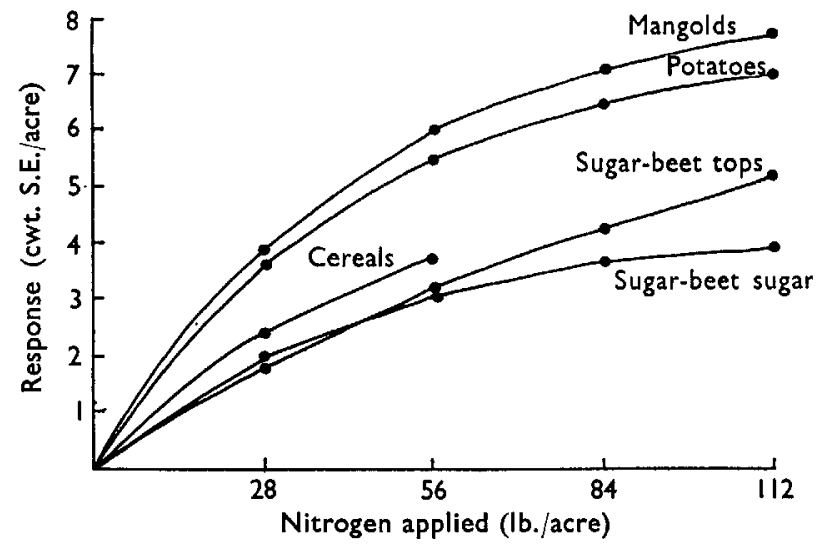

Fig. I. Response curves to nitrogen application (from Yates \& Boyd, 1949). 
The curves for cereals and root crops approximately fitted the same logarithmic curve represented by the following equation given by Crowther \& Yates (194I): $\mathrm{y}=$ yo $+\mathrm{d}\left(\mathrm{I}-\mathrm{I}^{-\mathrm{kx}}\right)$, where $\mathrm{y}=$ expected yield, yo $=$ yield without $\mathrm{N}$, $\mathrm{d}=$ limiting response, $\mathrm{k}=$ constant $(\mathrm{I} \cdot \mathrm{I}$ for cereals and root crops) and $\mathrm{x}=$ cwt. N/acre.

In simple terms, this equation means that for cereals and roots each successive dressing of $0.25 \mathrm{cwt}$. $\mathrm{N}$ increased the yield by $53 \%$ of the previous increment.

The response of sugar-beet tops to nitrogen fitted the same basic equation but the constant $\mathrm{k}$ was 0.4 instead of $\mathrm{I} \cdot \mathrm{I}$. For each successive fertilizer input of $0.25 \mathrm{cwt}$. N the yield increase was then $78 \%$ of the previous increment. Yates \& Boyd (1949) state that this equation also fits the response of other leafy crops such as kale. This basic distinction between the response of leafy crops such as kale and sugarbeet tops on the one hand and cereals and roots on the other should be stressed.

Cereal grain : the timing of nitrogen applications. Amongst the management factors, the timing of the nitrogen application can have a marked effect on the increase in yield at any particular fertilizer level. With winter-sown cereals most workers (e.g. Halliday, 1948; Watson, I939) agree that the use of nitrogen on the seed-bed in autumn is generally wasteful because of winter leaching, although good responses have been obtained on occasion.

In spring, nitrogen applied early in the season (February-March) may increase grain yield largely through an increase in the number of tillers and the consequent increase in the number of ears. In contrast, nitrogen applied in late spring (May) usually results in an increase in grain number per ear, with only a small increase in the number of ears (Garner \& Sanders, 1936). A split spring dressing, some in February and some in May, has therefore under experimental conditions usually been more efficient than the same amount of nitrogen applied in one dressing (Halliday, I948). The use of two spring top-dressings is not common in farm practice and its adoption would appear to lead to an improvement in nitrogen utilization.

The experimental evidence on the use of top-dressings on spring-sown cereals shows only a slight advantage over the normal practice of seed-bed application (Beesley \& Bullen, I956). However, where the fertilizer is being placed in contact with the seed, by a combined seed and fertilizer drill, only limited amounts of nitrogenous and potassic fertilizers may be applied in this way without retarding germination in a dry season (Reith, 1952). Where part of the nitrogen dressings has to be broadcast to avoid this risk it might be worth while to apply it as a later top-dressing.

Varietal responses. The introduction of new short-strawed varieties of cereals has made possible the use of heavier fertilizer applications than in the experiments quoted by Crowther \& Yates (194I) (Beesley \& Bullen, I956). Gardner (1953-4) has shown that stiff-strawed French wheats such as Hybrid 46 respond more efficiently to nitrogen top-dressings than do the older English varieties such as Little Joss which are less resistant to lodging. (Similarly Procter and Abed Kenia barley responded more efficiently to nitrogen than did the old variety Spratt Archer 
(Jones, I956)). Indeed the response of individual cereal varieties to nitrogen has become of such practical significance that the National Institute of Agricultural Botany is now testing new varieties under a range of nitrogen dressings.

Root crops. Root crops, such as potatoes and sugar-beet require a relatively high nitrogen supply during the early part of their growing season in order to produce a vigorous leaf system as early as possible. The latter part of the development of such crops consists of carbohydrate production for underground storage, which the plant does most efficiently with a relatively low nitrogen supply (Ulrich, I955). Nitrogen applied to root crops is therefore used most efficiently when applied to the seed-bed, since any late top-dressing would prolong leaf development at the expense of root and tuber storage. Although work in Holland has shown that on sandy soil an early top-dressing ( 3 weeks after planting) gave higher potato yields than when all the fertilizer was applied in the seed-bed (van der Paauw, I95I) this finding was not confirmed in similar experiments on a sandy soil in Nottinghamshire (Culpin \& Greaves, 1956).

Kale. The most important leaf-producing crop other than grass in British agriculture is kale. Work at Jealott's Hill (Imperial Chemical Industries Ltd, 1947) and Rothamsted Experiment Station (I937) shows that the average response in terms of starch equivalent is similar to that obtained for other crops; but the response curve is not clearly established. In view of the well-known relationship between nitrogen and leaf growth, and the long growing season of kale, the limited evidence available suggests that this crop is capable of using large amounts of nitrogen up to $200 \mathrm{lb}$./acre and that utilization is most efficient when the nitrogen is applied as a series of dressings throughout the season.

Leguminous crops. Peas, beans, lucerne and clovers have in general shown no responses to fertilizer nitrogen (Boyd, 1946). With pod-forming plants such as peas and beans, fertilizer may cause excess leaf development with a consequent reduction in flowering and grain yield. Moreover, with all leguminous crops the stimulation of any non-legume weeds by fertilizer may reduce yield.

Grassland. In contrast to cereals and roots, the grass crop consists of a succession of cuttings or grazings harvested over a period of 5-7 months of the year. Given suitable temperatures, water and other nutrient supply, the response of grassland depends on the total application of nitrogen, on its distribution over the season and on the clover content of the sward.

When grass is grazed a further factor is the return of nitrogen and other nutrients in the form of dung and urine. As it is proportional to the amount of herbage consumed an increase in production due to nitrogenous fertilizers increases the animal residues returned. For this reason responses under grazing conditions are often 40-60\% greater than under mowing treatments (Watkin, 1954; Walker, Orchiston \& Adams, 1954) since in effect some of the nitrogen is used more than once.

Mulder (1952) studied the influence of frequent applications of nitrogen to grassland at regular intervals throughout the season up to very high levels per acre ( $373 \mathrm{lb} . \mathrm{N} /$ acre/cut) and found that the response curve differed from month to month. This variation is related in part to the growth rhythm of the grass species and in part 
to the climatic conditions. At normal levels $\left(35^{-} 7 \mathrm{olb}\right.$. N/acre/cut) however, the response to nitrogen is relatively constant through the growing season (Mulder, I952; Holmes, 1954a) although in the early part of the season high responses are obtained only from early varieties of grass whereas late varieties give very small responses, and in extremely dry or wet weather the response is reduced.

Wind (1954) has recently shown that evapo-transpiration is not increased by the application of nitrogenous fertilizer to grassland, so that in fact the efficiency with which water is used is increased by nitrogen.

The grass - legume association. In practice, the nitrogen fertilization of grassland is extremely complicated since the normal grass-legume sward may derive directly or indirectly substantial quantities ( $150-250 \mathrm{lb}$. N/acre/year) of nitrogen from the clover. The contribution of clover is generally reduced by increasing nitrogen applications, but the magnitude of this effect depends on many factors, including time of year, grass species and frequency of defoliation.

Often the application of nitrogen in spring is particularly harmful to the grassclover sward since the earlier growing grass grows rapidly at that time and shades the clover. This was found by Watkin (1954) at Wye and by Holmes \& MacLusky (1955) at the Hannah Dairy Research Institute. On the other hand, Holmes (1954b) found on a predominantly grassy sward an almost linear response to nitrogen up to an application of $300 \mathrm{lb}$./acre/annum. From these data a diagrammatic representation showing the contribution of clover and fertilizer nitrogen has been constructed (Fig. 2). Watkin (1954) suggested that the practical implication of these results

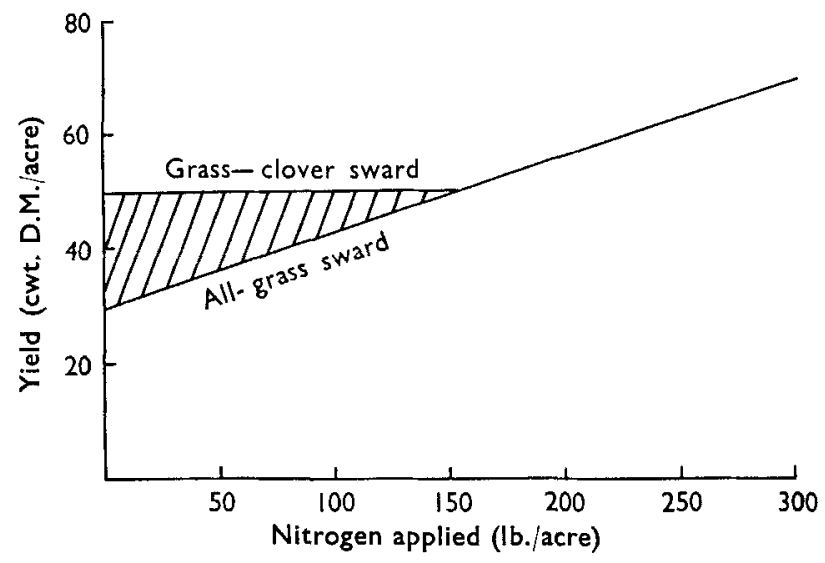

Fig. 2. Nitrogen response of grass-clover and all-grass swards (presented diagrammatically).

was that on clovery swards small or moderate amounts of nitrogen gave poor responses whereas heavy applications gave good responses since the complicating factor, suppression, no longer existed under the latter conditions. If this is so, the most efficient use of nitrogen is obtained by concentrating heavy dressings on a proportion of the grassland acreage and encouraging clover on the remaining area rather than using small dressings over the whole acreage as is the common practice in this country. Watkin's data clearly supported this conclusion but it is not wholly 
supported by other information (Holmes \& MacLusky, 1955). It is probable however, that the liberal use of nitrogen on early or highly responsive grasses such as Italian rye-grass or cocksfoot, and the encouragement in other fields of clover grown with grasses tolerant to it, such as timothy and meadow fescue, will give the most efficient overall utilization of nitrogen.

Comparison of grass and other crops. It is of interest to compare the nitrogen response of a grass sward with those already described for arable crops. Responses of from $5 \mathrm{lb}$. dry matter/lb. N on clovery swards to $25 \mathrm{lb}$. dry matter/lb. N on highly responsive grassy swards have been reported (Boyd \& Lessells, I954; Holmes \& MacLusky, 1955). In Fig. 3 the grass response curve is assumed to be linear from

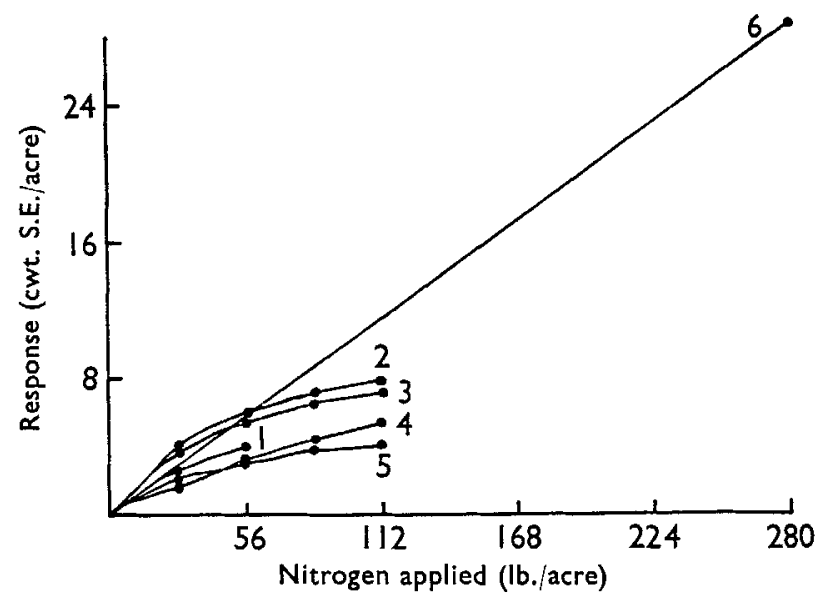

Fig. 3. Response curves to nitrogen application. 1, cereals; 2, mangolds; 3, potatoes; 4, sugar-beet tops; 5 , sugar-beet sugar; 6 , grass.

o to $280 \mathrm{lb}$. N. Although this is not strictly true departure from linearity is negligible, An average response of $15 \mathrm{lb}$. dry matter or $10 \mathrm{lb}$. S.E. per $\mathrm{lb}$. $\mathrm{N}$ has been adopted, which is in reasonable agreement with the findings of Boyd \& Lessells (1954), Walker et al. (1954), Holmes \& MacLusky (1954, 1955) and Watkin (1954). When the curve is compared with the curves for arable crops the outstanding capacity of grass to respond to large amounts of nitrogen is obvious.

Table I. Cost of producing additional grass with fertilizer*

\begin{tabular}{|c|c|c|}
\hline \multirow[b]{2}{*}{$\begin{array}{l}\text { Net response per } \\
\text { lb. nitrogen } \\
\text { (lb. dry matter) }\end{array}$} & \multicolumn{2}{|c|}{ Cost } \\
\hline & $\begin{array}{c}\text { Grass dry matter } \\
\text { (f/ton) }\end{array}$ & $\begin{array}{c}\text { S.E. } \\
\text { (f/ton) }\end{array}$ \\
\hline 5 & $25 \cdot 0$ & $45 \cdot 5$ \\
\hline IO & $12 \cdot 5$ & $22 \cdot 7$ \\
\hline 15 & $8 \cdot 4$ & $15 \cdot 2$ \\
\hline 20 & $6 \cdot 2$ & II.4 \\
\hline 25 & $5 \cdot 0$ & $9 \cdot I$ \\
\hline
\end{tabular}

* Fertilizer prices are those current in Britain in 1956. It is assumed that $\mathrm{N}, \mathrm{P}_{2} \mathrm{O}_{5}$ and $\mathrm{K}_{2} \mathrm{O}$ are applied in the weight ratio $3: 1: 3$. 
To return to the subject of farm-management economics, it is of interest to compare the cost of starch equivalent produced from the use of nitrogen on grass with figures for other feeds (Hamilton, I 955-6). If the $15 \mathrm{lb}$. dry matter produced by $\mathrm{r} \mathrm{lb} . \mathrm{N}$ is equivalent to Io lb. S.E., Table I shows that the cost per ton of S.E. is $\oint_{1} 5$, which is not much higher than Hamilton's figure of $\oint_{1}$ I for normal grazing and $\oint_{1}$ f for early bite grazing and compares favourably with that of any other feed. Moreover, as already noted, there is no evidence of diminishing returns up to very high levels of nitrogen application. There is abundant evidence, therefore, that cheap cattle food can be produced by the efficient use of nitrogen on grassland. Full exploitation of this knowledge depends on a mastery of the techniques of grass utilization, a subject outwith the scope of this paper.

\section{REFERENCES}

Beesley, D. W. \& Bullen, E. R. (1956). Exp. Husb. no. r, p. I8.

Boyd, D. A. (1946). Emp. F. exp. Agric. 14, 195.

Boyd, D. A. \& Lessells, W. J. (1954). 7. Brit. Grassl. Soc. 9, 7.

Crowther, E. M. \& Yates, F. (I94I). Emp. F. exp. Agric. 9, 77.

Culpin, S. \& Greaves, D. W. B. (1956). Exp. Husb. no. I, p. 44.

Gardner, H. W. (1953-4). F. Minist. Agric. 6o, 233.

Garner, F. \& Sanders, H. G. (1936). F. Agric. Sci. 26, 316.

Halliday, D. J. (1948). Bull. Fealott's Hill Res. Sta. no. 6.

Hamilton, R. A. (1955-6). F. Minist. Agric. 62, 374.

Holmes, W. (1954a). Yearb. Green Crop Dry. Res. Ass. p. 5 r.

Holmes, W. (I954b). F. Brit. Grassl. Soc. 9, I7.

Holmes, W. \& MacLusky, D. S. (r954). F. agric. Sci. 45, 129.

Holmes, W. \& Maclusky, D. S. (1955). J. agric. Sci. 46, 267.

Imperial Chemical Industries Ltd (1947). Bull. fealott's Hill Res. Sta. no. 5, revised.

Jones, P. J. (1956). Exp. Husb. no. I, p. Io.

Mulder, E. G. (1952). Int. Grassld Congr. vi. Pennsylvania, p. 740.

Reith, J. W. S. (1952). Emp. F. exp. Agric. 20, 103.

Rothamsted Experiment Station (I937). Rep. Rothamst. exp. Sta. p. 47.

Ulrich, A. (1955). Plant Physiol. 30, 250.

van der Paauw, F. (1951). Landbouwk. Tijdschr., 's-Grav., 63, 234.

Walker, T. W., Orchiston, H. D. \& Adams, A. F. R. (1954). F. Brit. Grassl. Soc. 9, 249.

Watkin, B. R. (1954). F. Brit. Grassl. Soc. 9, 35.

Watson, D. J. (1939). Y. agric. Sci. 29, 379.

Wind, G. P. (1954). In European Grassland Conference, Paris 21-24 June 1954, p. 195. Paris: The European Productivity Agency of the Organisation for European Economic Co-operation.

Yates, F. \& Boyd, D. A. (1949). Agric. Progr. 24, 14.

\section{Fertilizer nitrogen and milk production from grassland}

\section{A review of experience on commercial farms}

\section{By A. S. BARker, Central Agricultural Control, Imperial Chemical Industries Limited, 2 Buckingham Gate, London, S.W.I}

The resolution of problems of productivity in farming involves two distinct phases in the collection of the information required to establish and define improved efficiency. The first phase may be described as purely technical and is concerned with the accumulation of physical data by research and experiments in which the 